and without a history of depression, anxiety or insomnia ranged between $0-0.34$ for WOMAC Pain and Physical Function and 0 - 0.19 for PGA-OA.

Conclusion: Patients with a history of depression, anxiety, or insomnia did not appear to experience dampened improvements in pain or function with tanezumab or NSAID, as compared to those without. REFERENCES:

[1] Schnitzer T, et al. JAMA. 2019;322(1):37-48;

[2] Berenbaum F, et al. Ann Rheum Dis. 2020;79(6):800-10;

[3] Schnitzer T, et al. Semin Arthritis Rheum. 2020;50(3):387-93;

[4] Hochberg M, et al. Arthritis Rheumatol. In Press;

[5] Sharma A, et al. Open Access Rheumatol. 2016;31(8):103-13;

[6] Mallen C, et al. PLoS Med. 2017;14(4):e1002273;

[7] Campbell C, et al. Arthritis Care Res. 2015;67(10):1387-96.

Acknowledgements: Study sponsored by Pfizer and Eli Lilly and Company. Editorial support was provided by Jennifer Bodkin of Engage Scientific Solutions and funded by Pfizer and Eli Lilly and Company.

Disclosure of Interests: Philip J Mease Speakers bureau: AbbVie, Amgen Bristol Myers Squibb, Celgene, Janssen, Eli Lilly and Company, Novartis, Pfizer, UCB, Consultant of: AbbVie, Amgen, Boehringer Ingelheim, Bristol Myers Squibb, Celgene, Galapagos, Gilead, GlaxoSmithKline, Janssen, Eli Lilly and Company, Novartis, Pfizer, Sun, UCB, Grant/research support from: AbbVie, Amgen, Bristol Myers Squibb, Celgene, Janssen, Eli Lilly and Company, Novartis, Pfizer, Sun, UCB, Theresa Mallick-Searle Speakers bureau: Allergan, Abbvie, Eli Lilly and Company, Salix, Consultant of: Pfizer, Eli Lilly and Company, Elizabeth Johnston Shareholder of: Eli Lilly and Company, Employee of: Eli Lilly and Company, Lars Viktrup Shareholder of: Eli Lilly and Company, Employee of: Eli Lilly and Company, Dominique Menuet Employee of: Pfizer, Ruoyong Yang Employee of: Pfizer, Robert J Fountaine Shareholder of: Pfizer, Employee of: Pfizer. DOI: 10.1136/annrheumdis-2021-eular.166

\section{POS1089 1 ASSOCIATION BETWEEN PAIN SEVERITY AND HEALTHCARE UTILIZATION IN AN OSTEOARTHRITIS POPULATION: AN 18-YEAR RETROSPECTIVE COHORT STUDY}

J. Graham ${ }^{1}$, T. Novosat ${ }^{2}$, H. Sun ${ }^{3}$, B. Piper ${ }^{1,4}$, J. Boscarino ${ }^{5}$, V. Duboski ${ }^{1}$, M. Kern ${ }^{1}$, E. Wright ${ }^{1}$, R. Robinson ${ }^{6}$, E. Casey ${ }^{7}$, C. Beck ${ }^{7}$, J. Hall ${ }^{8}$, P. Schepman ${ }^{9}{ }^{1}$ Geisinger, Center for Pharmacy Innovation and Outcomes, Danville, United States of America; ${ }^{2}$ Geisinger, Interventional Pain, Danville, United States of America; ${ }^{3}$ Geisinger, Biostatistics Core, Danville, United States of America; ${ }^{4}$ Geisinger Commonwealth School of Medicine, Department of Medical Education, Scranton, United States of America; ${ }^{5}$ Geisinger, Department of Population Health Sciences, Danville, United States of America; ${ }^{6}$ Eli Lilly \& Co., Lilly Research Labs, Indianapolis, United States of America; ${ }^{7}$ Pfizer, Inc., Global Medical Affairs, New York, United States of America; ${ }^{8}$ Eli Lilly \& Co., Global/US Medical Affairs, Indianapolis, United States of America; ${ }^{9}$ Pfizer, Inc., Global HEOR, New York, United States of America

Background: Osteoarthritis $(O A)$ is a common disease that varies in severity among patients. A standardized definition to classify patients into different severity levels is lacking, however, due to the disease's complex pathogenesis and presentation. Prior studies have shown associations between pain severity and higher healthcare resource utilization (HRU) and costs. We investigated an association between pain severity and higher healthcare resource utilization by examining the use of specific OA-related treatments across pain intensity levels in a large, integrated health system's OA population over an 18-year period. Objectives: Our aim was to compare use of medications and other treatments among OA patients experiencing mild, moderate, or severe pain.

Methods: This was a retrospective study of electronic health records from 2001 to 2018 at Geisinger, an integrated health system in Pennsylvania. Patients were included with a diagnosis code for OA (ICD-9: 715. ${ }^{*}$, ICD-10 M15-19) on a problem list or encounter or an OA-specific procedure (hip or knee replacement, arthroscopy or injection). We examined pain scores (0-10 scale, with 10 being worst pain) taken after the first $O A$ diagnosis date and defined pain episodes starting on the pain score's date and lasting for 90 days. If a new pain score was measured before 90 days elapsed, the episode was extended for an additional 90 days, with this process repeated as necessary. Each episode was categorized as mild (pain score 0-3), moderate (4-6), or severe (7-10) based on initial score, and patients could contribute multiple episodes to the analysis. Descriptive statistics were used to quantify treatment utilization during each patients' mild, moderate and severe episodes. Percentages of patients who had any use of 10 medication types (tramadol, non-tramadol opioids, nonsteroidal anti-inflammatory drugs (NSAIDs), injectable corticosteroids, acetaminophen, salicylates, duloxetine, homeopathic medications, other topical medications, and other over-the-counter (OTC) medications were compared across pain episode types. Percentages of patients with knee or hip surgeries, spine or joint imaging procedures (x-ray, computed tomography or magnetic resonance) and consults to OA-related care (pain management, orthopedics or physical medicine and rehabilitation) were also compared. All analyses used logistic regression with p-values $<0.05$ considered significant.

Results: We identified 290,897 patients with OA, representing $34 \%$ of the health system population in $2018 ; 58 \%$ were female with mean age of 49 years and mean BMI of $30.5 \mathrm{~kg} / \mathrm{m} 2$. A total of 801,144 pain episodes were defined, with $75 \%$ of patients having at least one pain score. The two most frequently occurring pain scores were $0(17 \%)$ and $5(13 \%)$, and pain episodes were classified as $43 \%$ mild, $32 \%$ moderate and $25 \%$ severe. Significantly higher percentages of patients used certain medication types (NSAIDs, injectable corticosteroids, non-tramadol opioid, duloxetine) in both moderate and severe pain episodes as compared to mild episodes, but other medication types were less likely to be used as pain severity increased (acetaminophen, salicylates, homeopathic medications, other OTC medications). Knee or hip surgeries, imaging, and consults to OA-related specialists were all consistently significantly more likely to occur in patients during moderate or severe pain episodes versus mild episodes (relative risk ratios of $1.76,1.25$ and 1.35 for moderate vs mild, respectively, and 2.00, 1.44 and 1.46 for severe vs mild, all $p$-values $<0.05$ ).

Conclusion: While pain is generally recognized to be a subjective measure that could be influenced by other unmeasured factors and can be confounded with treatment effectiveness, it is nevertheless the primary symptom of OA. It is important to understand the relationship between pain intensity and treatment utilization, and our results support an overall association between pain and utilization but provide new details on the extent to which it depends on specific utilization type.

Acknowledgements: Pfizer and Eli Lilly and Company for sponsoring this study. Disclosure of Interests: Jove Graham Grant/research support from: I am an employee of Geisinger which received financial support from Pfizer and Eli Lilly and Company in connection with the development of this abstract, Tonia Novosat Grant/research support from: I am an employee of Geisinger which received financial support from Pfizer and Eli Lilly and Company in connection with the development of this abstract, Haiyan Sun Grant/research support from: I am an employee of Geisinger which received financial support from Pfizer and Eli Lilly and Company in connection with the development of this abstract, Brian Piper Grant/research support from: I am an employee of Geisinger which received financial support from Pfizer and Eli Lilly and Company in connection with the development of this abstract, Joseph Boscarino Grant/research support from: I am an employee of Geisinger which received financial support from Pfizer and Eli Lilly and Company in connection with the development of this abstract Vanessa Duboski Grant/research support from: I am an employee of Geisinge which received financial support from Pfizer and Eli Lilly and Company in connection with the development of this abstract, Melissa Kern Grant/research suppor from: I am an employee of Geisinger which received financial support from Pfize and Eli Lilly and Company in connection with the development of this abstract, Eric Wright Grant/research support from: I am an employee of Geisinger which received financial support from Pfizer and Eli Lilly and Company in connection with the development of this abstract, Rebecca Robinson Shareholder of: El Lilly \& Co., Employee of: Eli Lilly \& Co., Edward Casey Shareholder of: Pfizer, Inc., Paid instructor for: As an employee of Pfizer, Inc. this is part of my role. Employee of: Pfizer, Inc., Craig Beck Shareholder of: Pfizer, Inc., Employee of: Pfizer, Inc., Jerry Hall Shareholder of: Eli Lilly \& Co., Employee of: Eli Lilly \& Co., Patricia Schepman Shareholder of: Pfizer, Inc., Employee of: Pfizer, Inc. DOI: 10.1136/annrheumdis-2021-eular.523

\begin{tabular}{l|l}
\hline POS1090 & ASSOCIATION BETWEEN ANTIBIOTIC USE AND \\
KNEE PAIN AND FUNCTION IN OA: DATA FROM THE \\
OSTEOARTHRITIS INITIATIVE
\end{tabular}

1. Shirinsky ${ }^{1}$, V. Zagainova ${ }^{2}$, V. Shirinsky ${ }^{1} .{ }^{1}$ Research Institute of Fundamental and Clinical Immunology, Laboratory of Clinical Immunopharmacology, Novosibirsk, Russian Federation; ${ }^{2}$ Research Institute of Fundamental and Clinical Immunology, Rheumatology Unit, Novosibirsk, Russian Federation

Background: Recently, gut dysbiosis has been linked with joint pain in osteoarthritis (OA) (1). Thus, it can be hypothesized that antibiotic use impacts symptoms of OA. To date, there have been no studies assessing association between the intake of antibiotics and clinical manifestations of knee OA.

Objectives: To evaluate association between the use of antibiotics and OA-related knee pain and function.

Methods: For the current study we used 4-year longitudinal data obtained from the Osteoarthritis Initiative (OAI) progression $(n=1390)$ and incidence $(n=3284$ subcohorts, which are publically available at https://oai.nih.gov. The outcome variables studied were Western Ontario McMaster Osteoarthritis Index (WOMAC) pain and function subscales. To acquire information about the use of antibiotics, a medication inventory method was used. We excluded participants who used antibiotics at or 30 days prior to baseline (a "new-user" design). Antibiotic users were defined as those with at least one recorded use during first four years of the study. The participants were matched into antibiotic users/non-users pairs using genetic matching based on various demographic and clinical characteristics. The outcomes were assessed at baseline and annually until year 4. Generalized 